\title{
Mandel-Bar Sets of Inverse Complex Function
}

\author{
Yashwant S Chauhan \\ Asst. Professor \\ Computer Science \& Engg. \\ Department \\ G. B. Pant Engg. College, \\ Pauri Garhwal (India)
}

\author{
Rajeshri Rana \\ Asst. Professor \\ Applied Science and Humanities \\ Department \\ G. B. Pant Engg. College, \\ Pauri Garhwal (India)
}

\author{
Ashish Negi \\ Asst. Professor \\ Computer Science \& Engg. \\ Department \\ G. B. Pant Engg. College, \\ Pauri Garhwal (India)
}

\begin{abstract}
We introduce in this paper the dynamics of Relative Superior Mandel-bar sets of inverse complex function for Ishikawa iteration. The $z$ plane fractal images generated from the generalized transformation function $z \rightarrow\left(z^{n}+c\right)^{-1}$ for $n \geq 2$ are analyzed.
\end{abstract}

Keywords: Complex dynamics, Ishikawa Iteration, Relative Superior Mandel-bar sets

\section{INTRODUCTION}

The object Mandelbrot set given by Mandelbrot in 1979 and its relative object Julia set have become a wide and elite area of research nowadays due to their beauty and complexity of their nature.

Several papers have used escape-time methods to produce images of fractals based on the complex mapping $z \rightarrow\left(z^{n}+c\right)^{-1}$, where exponent $n$ is a positive integer. Recently, the generalized transformation function $z \rightarrow z^{-n}+c$ for positive integer values of $n$ has been considered by K. W. Shirriff [20].On the other hand, Shizuo [14], has presented the various properties of Multicorns and Tricorns for simple complex function, $z \rightarrow z^{2}+c$ where $z$ and $c$ are complex quantities. Shizuo[15] has also quoted the Multicorns as the generalized Tricorn or the Tricorn of higher order.

The dynamics of antipolynomial $z \rightarrow \vec{z}^{d}+c$ of complex polynomial $z^{d}+c$, where $d \geq 2$, leads to interesting Tricorn and Multicorns antifractals with respect to function iteration (see [6] and [14, 15]). Multicorns are symmetrical objects. Their symmetry has been studied by Lau and Schleicher [11].

The study of connectedness locus for antiholomorphic polynomials $\vec{z}^{2}+c$ defined as Tricorn, coined by Milnor, plays intermediate role between quadratic and cubic polynomials. Crowe etal.[4] considered it as in formal analogy with Mandelbrot set and named it as Mandel-bar set and also brought its features bifurcations along axes rather than at points. Milnor [13] found it as a real slice of cubic connected locus. Winters [21] showed it as boundary along the smooth arc.

In this paper, we investigate the dynamics of the Mandel-bar set for the transformation of the function $z \rightarrow\left(z^{n}+c\right)^{-1}$, for $n \geq 2$, and analyze the $z$ plane fractal images generated from the iterations of this function using Ishikawa iteration procedure and analyze the drastic changes that occur in the visual characteristics of the images from $n=2,3,4, \ldots$

\section{PRELIMINEARIES}

\subsection{Mandel-bar Set:}

Following the Milnor's [13] study, Shizuo [14] has defined the Tricorn, as the connectedness locus for antiholomorphic polynomials, $z^{\prime n}+c$, where $n=2$. We here define the Mandel-bar set as follows:

Definition2.1: The Mandel-bar set $A_{c}$, for the quadratic $A_{c}(z)=z^{\prime n}+c$ is defined as the collection of all $c \in C$ for which the orbit of the point 0 is bounded, that is, $A_{c}=\left\{c \in C: A_{c}(0)_{n=0,1,2,3, \ldots}\right.$ is bounded $\}$.

An equivalent formulation is $A_{c}=\left\{c \in C: A_{c}(0)\right.$ not tends to $\infty$ as $\left.n \rightarrow \infty\right\}$

As quoted by Devaney [6], iterations of the function $A_{c}=z^{\prime 2}+c$, using the Escape Time Algorithm, results in many strange and surprising structures. Devaney [6] has named it Tricorn and observed that $f\left(z^{\prime}\right)$, the conjugate function of $f(z)$, is antipolynomial. Further, its second iterates is a polynomial of degree 4. Taking the initial choice $z_{0}$, one can iterate $A_{c}^{1}(z)$, resulting $z_{1}$ equals $z_{0}^{\prime 2}+c$, which can be written as $\left\{\left|z_{0}\right|^{2} / z_{0}\right\}^{2}+c$, since $z_{0}^{\prime} * z_{0} \quad$ is equivalent to $\left\{\left|z_{0}\right|^{2}\right\}$, which gives $z_{1}$ equals 
$\left\{\left|z_{0}\right|^{4} / z_{0}{ }^{2}\right\}+c$. Using this value one can state the conjugate of $z_{1}$ as $z_{1}^{\prime}=\left\{\left|z_{0}\right|^{4} / z_{0}^{\prime 2}\right\}+c^{\prime}$, resulting $z_{0}{ }^{2}+c^{\prime}$. Now the second iterate can be stated as $A^{2}{ }_{c}(z)$ which is equal to $z_{1}^{\prime 2}+c$. On simplifying, one can get $\left\{z_{0}{ }^{2}+c^{\prime}\right\}^{2}+c$. Further $z_{0}{ }^{4}+2 z_{0}{ }^{2} c^{\prime}+c^{\prime 2}+c$, which is a polynomial of degree 4 in $z$. The critical point for $A_{c}$ is 0 , since $c=A_{c}(0)$ has only one preimage whereas any other $w \in C$, has two preimages.

Definition2.2: Ishikawa Iteration [10]: Let $X$ be a subset of real or complex numbers and $f: X \rightarrow X$. For $x_{0} \in X$, we have the sequences $\left\{x_{n}\right\}$ and $\left\{y_{n}\right\}$ in $\mathrm{X}$ in the following manner:

$y_{n}=s_{n}^{\prime} f\left(x_{n}\right)+\left(1-s_{n}^{\prime}\right) x_{n}$

$x_{n+1}=s_{n} f\left(y_{n}\right)+\left(1-s_{n}\right) x_{n}$

where $0 \leq s_{n}^{\prime} \leq 1,0 \leq s_{n} \leq 1$ and $\quad s_{n}^{\prime} \& \quad s_{n}$ are both convergent to non zero number.

Definition 2.3[19]: The sequences $x_{n}$ and $y_{n}$ constructed above is called Ishikawa sequences of iterations or Relative superior sequences of iterates. We denote it by $R S O\left(x_{0}, s_{n}, s_{n}^{\prime}, t\right)$.

Notice that $\operatorname{RSO}\left(x_{0}, s_{n}, s_{n}^{\prime}, t\right)$ with $s_{n}^{\prime}=1 \quad$ is $R S O\left(x_{0}, s_{n}, t\right)$ i.e. Mann's orbit and if we place $s_{n}=s_{n}^{\prime}=1$ then $\operatorname{RSO}\left(x_{0}, s_{n}, s_{n}^{\prime}, t\right)$ reduces to $O\left(x_{0}, t\right)$.

We remark that Ishikawa orbit $R S O\left(x_{0}, s_{n}, s_{n}^{\prime}, t\right)$ with $s_{n}^{\prime}=1 / 2$ is Relative Superior orbit. Now we define Mandelbrot sets for function with respect to Ishikawa iterates. We call them as Relative Superior Mandelbrot sets.

Definition 2.4[19]: Relative Superior Mandelbar set RSMB for the function of the form $Q_{c}(z)=z^{n}+c$, where $\mathrm{n}=1,2,3,4 \ldots$ is defined as the collection of $c \in C$ for which the orbit of 0 is bounded i.e.

$$
R S M B=\left\{c \in C: Q_{c}^{k}(0): k=0,1,2 \ldots\right\} \text { is }
$$

bounded.

Here we present the study of Relative Superior Mandelbar set and Relative Superior Julia set by using the Escape Time Algorithm with respect to Ishikawa Iterates.

Now, we define escape criterions for these sets.
2.4 Escape Criterion: Fractals have been generated from $z \rightarrow z^{-n}+c$ using escape-time techniques, for example by Gujar etal. [7, 8] and Glynn [9]. We have used in this paper escape time criteria of Relative Superior Ishikawa iterates for function $z \rightarrow\left(z^{n}+c\right)^{-1}$.

We obtain here a general escape criterion for polynomials of the form $G_{c}(z)=z^{n}+c$

Escape Criterion for Quadratics: Suppose that $|z|>\max \left\{|c|, 2 / s, 2 / s^{\prime}\right\}, \quad$ then $\left|z_{n}\right|>(1+\lambda)^{n}|z|$ and $\quad\left|z_{n}\right| \rightarrow \infty$ as $n \rightarrow \infty$.So, $|z| \geq|c|$ and $|z|>2 / s$ as well as $|z|>2 / s^{\prime}$ shows the escape criteria for quadratics.

Escape Criterion for Cubics: Suppose $|z|>\max \left\{|b|,(|a|+2 / s)^{1 / 2},\left(|a|+2 / s^{\prime}\right)^{1 / 2}\right\}$

then $\left|z_{n}\right| \rightarrow \infty$ as $n \rightarrow \infty$. This gives an escape criterion for cubic polynomials

General Escape Criterion: Consider $|z|>\max \left\{|c|,(2 / s)^{1 / n},\left(2 / s^{\prime}\right)^{1 / n}\right\} \quad$ then $\left|z_{n}\right| \rightarrow \infty$ as $n \rightarrow \infty$ is the escape criterion. (Escape Criterion derived in [3] \& [19]).

Note that the initial value $z_{0}$ should be infinity, since infinity is the critical point of $z \rightarrow\left(z^{n}+c\right)^{-1}$. However instead of starting with $z_{0}=$ infinity, it is simpler to start with $z_{1}=c$, which yields the same result. (A critical point of $\mathrm{z} \rightarrow \mathrm{F}(\mathrm{z})+\mathrm{c}$ is a point where $\mathrm{F}^{\prime}(z)=0$ ). The role of critical points is explained in [1].

The purpose of this paper is to visualize the relative superior antifractals of the complex inverse function i.e., antifractals with respect to relative superior orbit and to analyze the pattern of symmetry among them.

\section{GEOMETRY OF RELATIVE SUPERIOR MANDELBAR SETS}

The results of plotting the Relative Superior Mandelbar set for the function $A_{c}$ using Ishikawa Iterates, gives us the half moon shaped like crescent structure, hence, it can be named as Relative Superior Mandelbar set for quadratic. Crowe et. al [4], has considered it in formal analogy with Mandelbrot set and named it "Mandelbar set". The general escape criterion for higher powers of polynomials, $A_{c}(z)=z^{\prime n}+c$ where $\mathrm{n}$ is the degree of the polynomial, is given as $\max \left\{|c|,(2 / s)^{1 / n},\left(2 / s^{\prime}\right)^{1 / n}\right\}$ This can be used as the escape criterion for the function $A_{c}(z)$.We derive Relative Superior Mandelbar sets using this escape criteria. We have used the same escape criterion for generating the new Mandelbar sets for quadratic 
function for which the condition is $\max \left\{|c|, 2 / s, 2 / s^{\prime}\right\}$.

The characteristics of the Relative Superior Julia set for a point inside the Relative Superior Mandelbar set can be given by observing the Relative Superior Mandelbar set. We know that, if $c$ lies in $A_{c}$, the orbit of 0.0 does not escape to infinity. Hence we can say that if $c$ does not lie in $A_{c}$ then the Relative Superior Julia set $J_{c}$ for Relative Superior Mandelbar set, is a Cantor set. The Relative Superior Julia set of $A_{c}$ is either connected or totally disconnected, depending on, whether the orbit of 0 is bounded or escapes to infinity. We know that every Relative Superior Julia set is either:

- A Primary Relative Superior Julia set, or

- A Secondary Relative Superior Julia set

Primary Relative Superior Julia set are the Relative superior Julia set for the points attached to the main body of the Relative Superior Mandelbar set, whereas the name secondary Relative Superior Julia set can be given to those Julia set which belongs to the parts attached to the main body. We study here the primary Relative Superior Julia set for Relative Superior Mandelbar set (See Section 6). Further, we observe that the Relative Superior Julia set for Relative superior Mandelbar set consists of all c-values for which $J_{c}$ is connected, or the orbit of 0.0 under $z^{\prime 2}+c$ does not tend to infinity.

We see that the Relative Superior Mandelbar set of quadratics consists of one crescent shaped body. Further, the Relative superior Mandelbar sets of higher polynomials contain the Main body having the number of parts attached to it less than that of Multicorns [4, 14, 15 \&16].

Here, we are presenting the observation in the study of the Relative Superior Mandelbar sets from the figures mentioned in Section 5.

\section{Relative Superior Mandelbar sets:}

- Here we notice that the number of body parts in the Relative Superior Mandelbar sets is n-1, where $\mathrm{n}$ is the power of $z^{\prime}$.

- As the value of $s$ tend to 1 and s' tends to 1 , the Relative Superior Mandelbar sets of order higher than two, have their main body get separated into n-1 equal parts which exists at some distance from each other.

- $\quad$ Starting with $A_{c}(z)=z^{\prime n}+c$, for $\mathrm{n}=2,3,4, \ldots$ and $\mathrm{s}<1$, s' $<1$ and applying the Ishikawa iterates we see that the Relative Superior Mandelbar sets of this function carries number of cuts in each crescent equals to $n+1$

- We also observe that for $n$ is odd we have symmetry about both $\mathrm{X}$ and $\mathrm{Y}$ axis but for $n$ is even the symmetry is maintained only along $\mathrm{X}$ axis.

Relative Superior Julia sets:
- Geometrical analysis of the Relative Superior Julia sets of inverse complex conjugate function shows that the boundary of the fixed point region forms a $(n-1)$ crescent shaped petals like parts.

- For each value of $c$, we can iterate the mapping and test whether the resulting sequence of $\mathrm{z}$ approaches a cycle or not. The points that lead to a cycle can be colored according to the length of the cycle and the points that never enter the cycle but wander chaotically are colored dark. The light color regions in the figures represent stable points while dark colored regions represent unstable points.

- Relative Superior Julia sets of inverse complex conjugate function for quadratic function shows ball shaped figure maintaining symmetry along $\mathrm{X}$ axis. For cubic function Relative Superior Julia sets shows symmetry along $\mathrm{X}$ and $\mathrm{Y}$ axes both. Moreover this function also describes reflection and rotational symmetry. The biquadratic function shows us the fascinating results. Here we have central planet with satellite like structures obtained that represents reflection as well as rotational symmetry.

\section{FIXED POINTS}

4.1 Fixed points of quadratic polynomial

Table 1: Orbit of $F(z)$ for $s=1, s^{\prime}=1$ at

$z_{0=}=-0.7596358795+0.006005097 i$

\begin{tabular}{|c|c|c|c|}
\hline $\begin{array}{c}\text { Number of } \\
\text { iteration } i\end{array}$ & $|\mathrm{~F}(\mathrm{z})|$ & $\begin{array}{c}\text { Number of } \\
\text { iteration } i\end{array}$ & $|\mathrm{~F}(\mathrm{z})|$ \\
\hline 1 & 0.75966 & 11 & 0.22073 \\
\hline 2 & 0.44694 & 12 & 0.22071 \\
\hline 3 & 0.37567 & 13 & 0.22067 \\
\hline 4 & 0.37069 & 14 & 0.22069 \\
\hline 5 & 0.16322 & 15 & 0.22068 \\
\hline 6 & 0.22445 & 16 & 0.22068 \\
\hline 7 & 0.22942 & 17 & 0.22068 \\
\hline 8 & 0.21663 & 18 & 0.22068 \\
\hline 9 & 0.22109 & 19 & 0.22068 \\
\hline 10 & 0.22115 & 20 & 0.22068 \\
\hline
\end{tabular}

Here we observe that the value converges to a fixed point after 15 iterations

Figure 1. Orbit of $F(z)$ for $s=1, s^{\prime}=1$ at $\mathrm{z}_{0=}=\mathbf{- 0 . 7 5 9 6 3 5 8 7 9 5 + 0 . 0 0 6 0 0 5 0 9 7 i}$

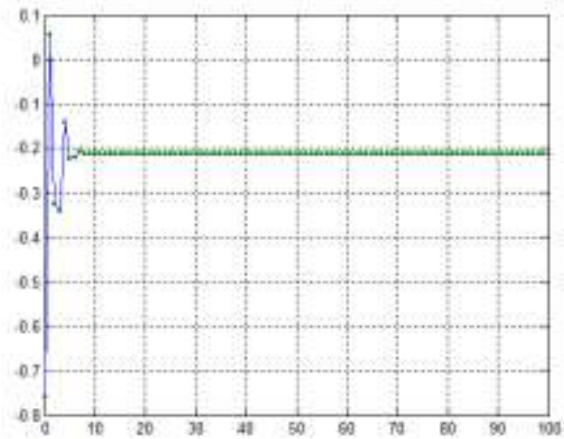


Table 2: Orbit of $F(z)$ for $\mathrm{s}=\mathbf{0 . 5}, \mathrm{s}^{\prime}=\mathbf{0 . 7}$ at $z_{0}=\mathbf{- 0 . 6 1 6 0 3 7 4 8 3 9 + 0 . 0 1 3 5 6 2 9 0 7 3 i}$

\begin{tabular}{|c|c|c|c|}
\hline $\begin{array}{c}\text { Number of } \\
\text { iteration } \mathrm{i}\end{array}$ & $|\mathrm{F}(\mathrm{z})|$ & $\begin{array}{c}\text { Number of } \\
\text { iteration } \mathrm{i}\end{array}$ & $|\mathrm{F}(\mathrm{z})|$ \\
\hline 1 & 0.61619 & 14 & 0.35866 \\
\hline 2 & 0.5189 & 15 & 0.35835 \\
\hline 3 & 0.288 & 16 & 0.35852 \\
\hline 4 & 0.43079 & 17 & 0.35842 \\
\hline 5 & 0.32218 & 18 & 0.35848 \\
\hline 6 & 0.37886 & 19 & 0.35845 \\
\hline 7 & 0.34703 & 20 & 0.35846 \\
\hline 8 & 0.36492 & 21 & 0.35845 \\
\hline 9 & 0.35484 & 22 & 0.35846 \\
\hline 10 & 0.36049 & 23 & 0.35846 \\
\hline 11 & 0.35732 & 24 & 0.35846 \\
\hline 12 & 0.3591 & 25 & 0.35846 \\
\hline 13 & 0.3581 & 26 & 0.35846 \\
\hline
\end{tabular}

Here we observe that the value converges to a fixed point after 22 iterations

Figure 2. Orbit of $F(z)$ for $\mathbf{s}=\mathbf{0 . 5}, \mathbf{s}^{\prime}=\mathbf{0 . 7}$ at $\mathrm{z}_{0}=\mathbf{- 0 . 6 1 6 0 3 7 4 8 3 9 + 0 . 0 1 3 5 6 2 9 0 7 3 i}$

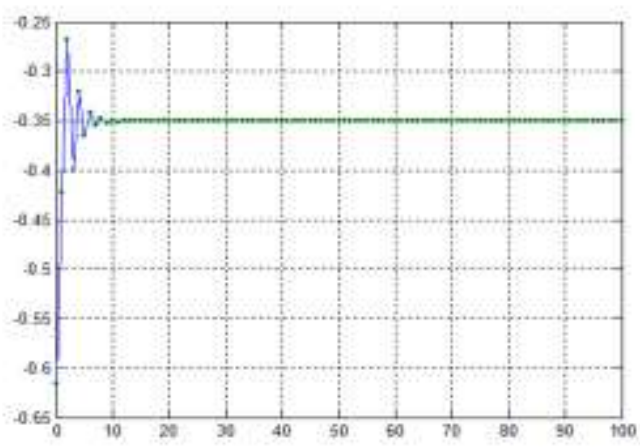

Table 3: Orbit of $\mathrm{F}(\mathrm{z})$ for $0.4, \mathrm{~s}^{\prime}=\mathbf{0 . 1}$ at $\mathrm{z}_{0}=\mathbf{- 0 . 0 4 1 6 4 3 9 0 1 3 9 + 0 . 0 0 6 0 0 5 0 9 7 i}$

\begin{tabular}{|c|c|c|c|}
\hline $\begin{array}{c}\text { Number of } \\
\text { iteration } \mathrm{i}\end{array}$ & $|\mathrm{F}(\mathrm{z})|$ & $\begin{array}{c}\text { Number of } \\
\text { iteration i }\end{array}$ & $|\mathrm{F}(\mathrm{z})|$ \\
\hline 1 & 0.042075 & 16 & 0.93234 \\
\hline 2 & 0.81996 & 17 & 1.001 \\
\hline 3 & 0.2836 & 18 & 0.94791 \\
\hline 4 & 1.101 & 19 & 0.96464 \\
\hline 5 & 0.52569 & 20 & 0.95734 \\
\hline 6 & 1.8414 & 21 & 0.95903 \\
\hline 7 & 1.031 & 22 & 0.95897 \\
\hline 8 & 0.74237 & 23 & 0.95875 \\
\hline 9 & 8.0956 & 24 & 0.9589 \\
\hline 10 & 4.8648 & 25 & 0.95884 \\
\hline 11 & 2.9397 & 26 & 0.95885 \\
\hline 12 & 1.8177 & 27 & 0.95885 \\
\hline 13 & 1.2423 & 28 & 0.95885 \\
\hline 14 & 0.97245 & 29 & 0.95885 \\
\hline 15 & 1.0586 & 30 & 0.95885 \\
\hline
\end{tabular}

Here the value converges to a fixed point after 26 iterations
Figure 3. : Orbit of $F(z)$ for $0.4, s^{\prime}=0.1$ at $z_{0}=\mathbf{- 0 . 0 4 1 6 4 3 9 0 1 3 9 + 0 . 0 0 6 0 0 5 0 9 7 i}$

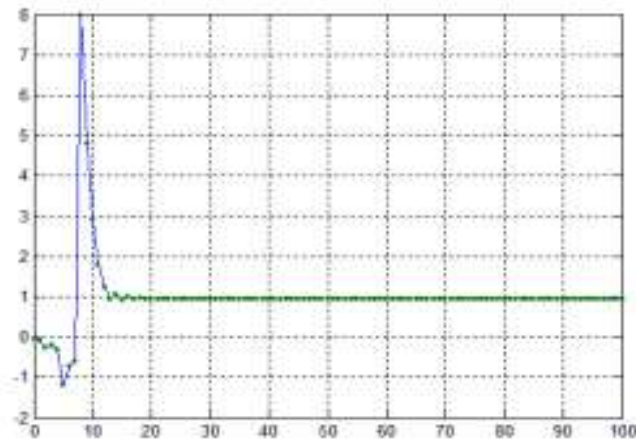

4.2 Fixed points of Cubic polynomial

Table 1: Orbit of $F(z)$ for $s=1, s^{\prime}=1$ at

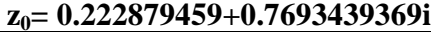

\begin{tabular}{|c|c|c|c|}
\hline $\begin{array}{c}\text { Number of } \\
\text { iteration } i\end{array}$ & $|\mathrm{~F}(\mathrm{z})|$ & $\begin{array}{c}\text { Number of } \\
\text { iteration } i\end{array}$ & $|\mathrm{~F}(\mathrm{z})|$ \\
\hline 1 & 0.80098 & 6 & 0.13547 \\
\hline 2 & 0.069844 & 7 & 0.13547 \\
\hline 3 & 0.13321 & 8 & 0.13547 \\
\hline 4 & 0.13536 & 9 & 0.13547 \\
\hline 5 & 0.13546 & 10 & 0.13547 \\
\hline
\end{tabular}

Here the value converges to a fixed point after 06 iterations

Figure 1 Orbit of $\mathrm{F}(\mathrm{z})$ for $\mathrm{s}=\mathbf{1}, \mathrm{s}^{\prime}=\mathbf{1}$ at $\mathrm{z}_{0}=0.222879459+0.7693439369 \mathrm{i}$

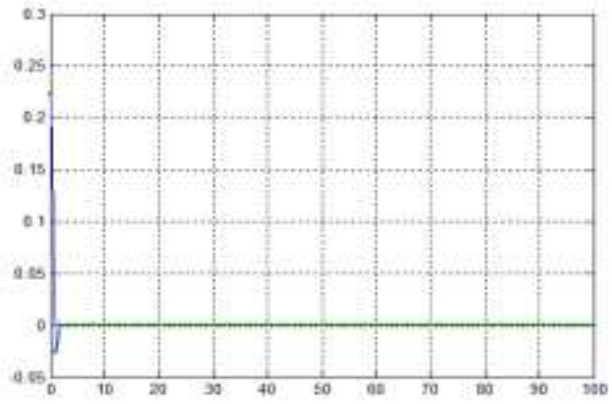

Table 2: Orbit of $\mathrm{F}(\mathrm{z})$ for $\mathrm{s}=\mathbf{0 . 4}, \mathrm{s}^{\prime}=\mathbf{0 . 2}$ at $\mathrm{Z}_{0}=\mathbf{- 0 . 0 1 8 9 7 0 4 7 0 5 + 0 . 0 2 8 6 7 8 5 2 7 8 9 \mathrm { i }}$

\begin{tabular}{|c|c|c|c|}
\hline $\begin{array}{c}\text { Number of } \\
\text { iteration } \mathrm{i}\end{array}$ & $|\mathrm{F}(\mathrm{z})|$ & $\begin{array}{c}\text { Number of } \\
\text { iteration } \mathrm{i}\end{array}$ & $|\mathrm{F}(\mathrm{z})|$ \\
\hline 18 & 0.6098 & 28 & 0.50274 \\
\hline 19 & 0.45643 & 29 & 0.50223 \\
\hline 20 & 0.52977 & 30 & 0.50252 \\
\hline 21 & 0.4871 & 31 & 0.50236 \\
\hline 22 & 0.51134 & 32 & 0.50245 \\
\hline 23 & 0.49733 & 33 & 0.5024 \\
\hline 24 & 0.50536 & 34 & 0.50243 \\
\hline 25 & 0.50073 & 35 & 0.50241 \\
\hline 26 & 0.50339 & 36 & 0.50242 \\
\hline 27 & 0.50186 & 37 & 0.50242 \\
\hline
\end{tabular}

We skipped 17 iterations and value converges to a fixed point after 36 iterations 
Figure 2 Orbit of $F(z)$ for $s=0.4, s^{\prime}=\mathbf{0 . 2}$ at $\mathrm{z}_{0}=\mathbf{- 0 . 0 1 8 9 7 0 4 7 0 5 + 0 . 0 2 8 6 7 8 5 2 7 8 9 i}$

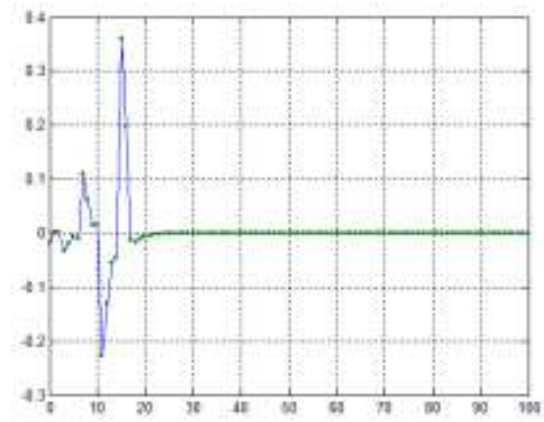

Table 3: Orbit of $F(z)$ for $\mathbf{s}=\mathbf{0 . 5}, \mathbf{s}^{\prime}=\mathbf{0 . 7}$ at

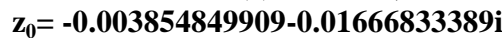

\begin{tabular}{|c|c|c|c|}
\hline $\begin{array}{c}\text { Number of } \\
\text { iteration } \mathrm{i}\end{array}$ & $|\mathrm{F}(\mathrm{z})|$ & $\begin{array}{c}\text { Number of } \\
\text { iteration } \mathrm{i}\end{array}$ & $|\mathrm{F}(\mathrm{z})|$ \\
\hline 1 & 0.017108 & 12 & 0.13646 \\
\hline 2 & 0.2116 & 13 & 0.13602 \\
\hline 3 & 0.096623 & 14 & 0.13627 \\
\hline 4 & 0.1598 & 15 & 0.13613 \\
\hline 5 & 0.12295 & 16 & 0.13621 \\
\hline 6 & 0.1439 & 17 & 0.13617 \\
\hline 7 & 0.13178 & 18 & 0.13619 \\
\hline 8 & 0.13872 & 19 & 0.13618 \\
\hline 9 & 0.13473 & 20 & 0.13619 \\
\hline 10 & 0.13702 & 21 & 0.13618 \\
\hline 11 & 0.1357 & 22 & 0.13618 \\
\hline
\end{tabular}

Here the value converges to a fixed point after 21 iterations

Figure 3 Orbit of $F(z)$ for $\mathbf{s}=\mathbf{0 . 5}, \mathbf{s}^{\prime}=\mathbf{0 . 7}$ at $z_{0}=\mathbf{- 0 . 0 0 3 8 5 4 8 4 9 9 0 9 - 0 . 0 1 6 6 6 8 3 3 3 8 9 i}$

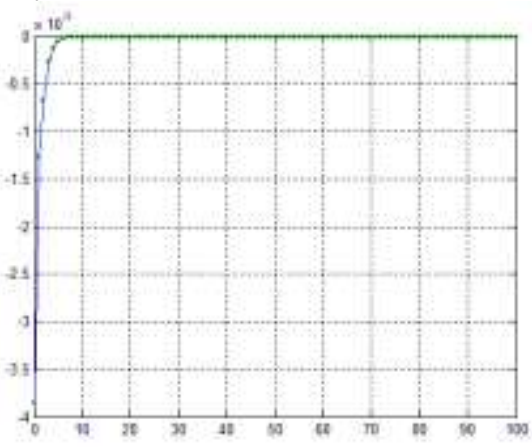

4.3 Fixed points of Bi-quadratic polynomial

Table 1: Orbit of $\mathrm{F}(\mathrm{z})$ for $\mathrm{s}=\mathbf{1}, \mathrm{s}^{\prime}=1$ at $\mathrm{z}_{0}=\mathbf{0 . 4 1 1 8 2 4 7 1 6 3 + 0 . 7 1 6 4 3 9 2 6 4 8 \mathrm { i }}$

\begin{tabular}{|c|c|c|c|}
\hline $\begin{array}{c}\text { Number of } \\
\text { iteration } i\end{array}$ & $|\mathrm{~F}(\mathrm{z})|$ & $\begin{array}{c}\text { Number of } \\
\text { iteration } i\end{array}$ & $|\mathrm{~F}(\mathrm{z})|$ \\
\hline 1 & 0.82637 & 4 & 0.062471 \\
\hline 2 & 0.0038329 & 5 & 0.062471 \\
\hline 3 & 0.06247 & 6 & 0.062471 \\
\hline
\end{tabular}

Here the value converges to a fixed point after 04 iterations
Figure 1 Orbit of $\mathrm{F}(\mathrm{z})$ for $\mathrm{s}=1, \mathrm{~s}^{\prime}=1$ at

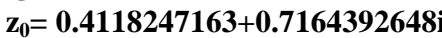

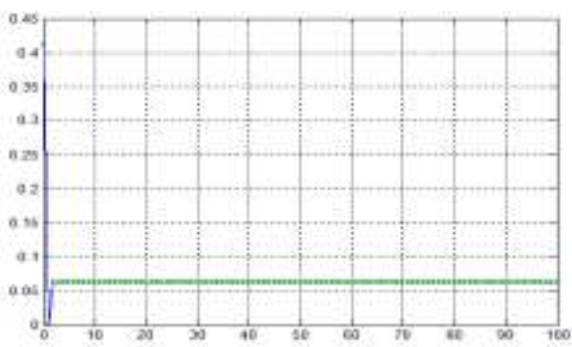

Table 2: Orbit of $\mathrm{F}(\mathrm{z})$ for $\mathrm{s}=\mathbf{0 . 4}, \mathrm{s}^{\prime}=\mathbf{0 . 2}$ at

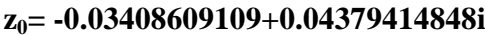

\begin{tabular}{|c|c|c|c|}
\hline $\begin{array}{c}\text { Number of } \\
\text { iteration } \mathrm{i}\end{array}$ & $|\mathrm{F}(\mathrm{z})|$ & $\begin{array}{c}\text { Number of } \\
\text { iteration } \mathrm{i}\end{array}$ & $|\mathrm{F}(\mathrm{z})|$ \\
\hline 1 & 0.055496 & 13 & 0.49886 \\
\hline 2 & 0.76449 & 14 & 0.50069 \\
\hline 3 & 0.31085 & 15 & 0.49959 \\
\hline 4 & 0.61364 & 16 & 0.50025 \\
\hline 5 & 0.43138 & 17 & 0.49986 \\
\hline 6 & 0.54122 & 18 & 0.50009 \\
\hline 7 & 0.47532 & 19 & 0.49995 \\
\hline 8 & 0.51481 & 20 & 0.50003 \\
\hline 9 & 0.49113 & 21 & 0.49998 \\
\hline 10 & 0.50532 & 22 & 0.50001 \\
\hline 11 & 0.49682 & 23 & 0.5 \\
\hline 12 & 0.50191 & 24 & 0.5 \\
\hline
\end{tabular}

Here the value converges to a fixed point after 23 iterations

Figure 2 Orbit of $\mathrm{F}(\mathrm{z})$ for $\mathrm{s}=\mathbf{0 . 4}, \mathrm{s}^{\prime}=\mathbf{0 . 2}$ at $z_{0}=-\mathbf{0 . 0 3 4 0 8 6 0 9 1 0 9 + 0 . 0 4 3 7 9 4 1 4 8 4 8 i}$

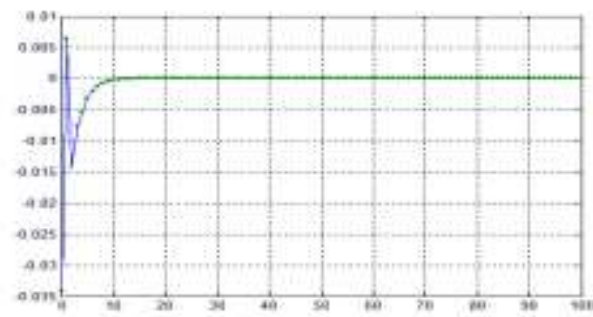

Table 3: Orbit of $F(z)$ for $\mathbf{s}=\mathbf{0 . 5}, \mathbf{s}^{\prime}=\mathbf{0 . 7}$ at $\mathrm{z}_{0}=\mathbf{- 0 . 0 1 8 9 7 0 4 7 0 5 - 0 . 0 0 1 5 5 2 7 1 3 2 9 6 \mathrm { i }}$

\begin{tabular}{|l|l|l|l|}
\hline $\begin{array}{l}\text { Number of } \\
\text { iteration } i\end{array}$ & $|\mathrm{~F}(\mathrm{z})|$ & $\begin{array}{l}\text { Number of } \\
\text { iteration } \mathrm{i}\end{array}$ & $|\mathrm{F}(\mathrm{z})|$ \\
\hline 1 & 0.019034 & 11 & 0.25855 \\
\hline 2 & 0.11937 & 12 & 0.2586 \\
\hline 3 & 0.19186 & 13 & 0.25863 \\
\hline 4 & 0.22649 & 14 & 0.25865 \\
\hline 5 & 0.24441 & 15 & 0.25865 \\
\hline 6 & 0.252 & 16 & 0.25865 \\
\hline 7 & 0.25581 & 17 & 0.25866 \\
\hline 8 & 0.25733 & 18 & 0.25866 \\
\hline 9 & 0.2581 & 19 & 0.25866 \\
\hline 10 & 0.25839 & 20 & 0.25866 \\
\hline
\end{tabular}


Here the value converges to a fixed point after 17 iterations

Figure 3. Orbit of $F(z)$ for $\mathbf{s}=\mathbf{0 . 5}, \mathbf{s}^{\prime}=\mathbf{0 . 7}$ at $z_{0}=\mathbf{- 0 . 0 1 8 9 7 0 4 7 0 5 - 0 . 0 0 1 5 5 2 7 1 3 2 9 6 i}$

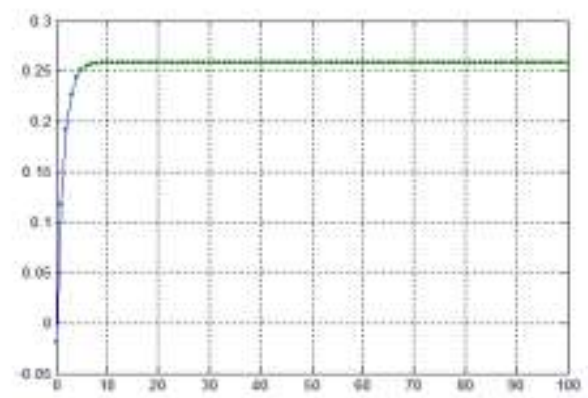

\section{GENERATION OF RELATIVE}

\section{SUPERIOR MANDELBAR SETS}

We generate Relative Superior Mandelbar sets for quadratic, cubic, biquadratic function and other higher order polynomials.

4.1 Relative Superior Mandelbar sets for Quadratic function:

Figure 1: Relative Superior Mandelbar set for $s=s^{\prime}=1$

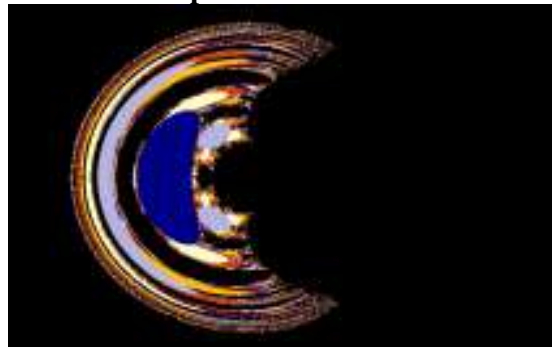

Figure 2: Relative Superior Mandelbar set for $\mathrm{s}=\mathbf{0 . 6}$,

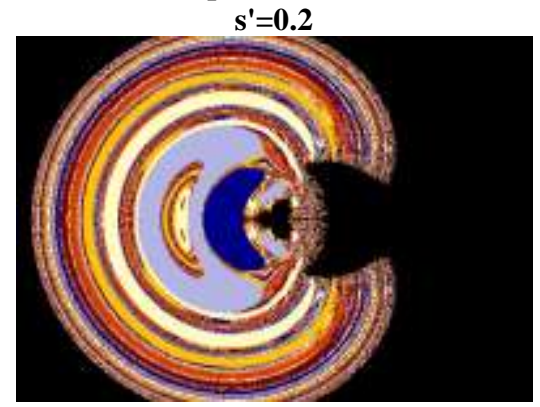

Figure 3: Relative Superior Mandelbar set for $s=0.5$, $\mathrm{s}^{\prime}=\mathbf{0 . 5}$

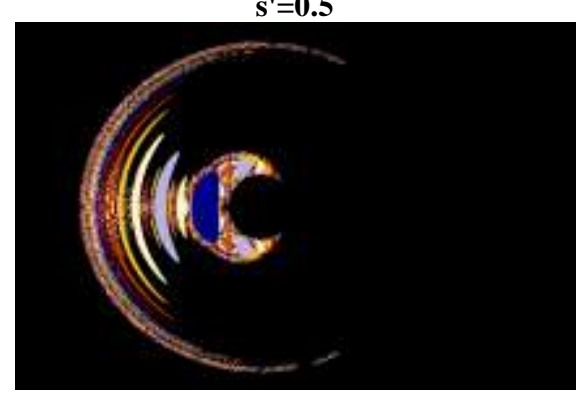

4.2. Relative Superior Mandelbar set for Cubic function:

Figure 1: Relative Superior Mandelbar set for $s=1, s^{\prime}=1$

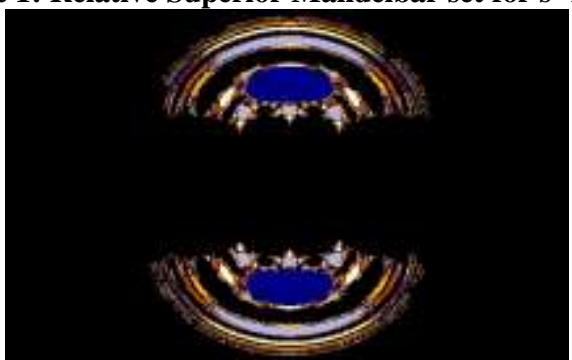

Figure 2: Relative Superior Mandelbar set for $s=0.4$, $\mathrm{s}^{\prime}=\mathbf{0 . 2}$

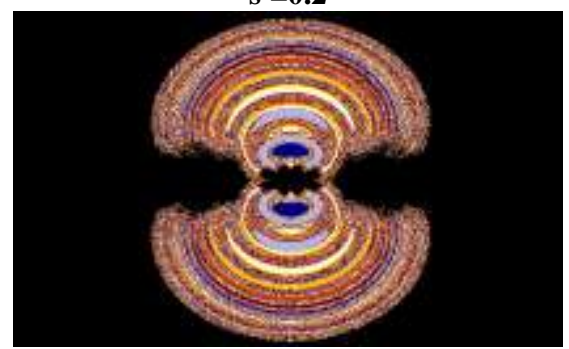

Figure 3: Relative Superior Mandelbar set for $s=0.5$,

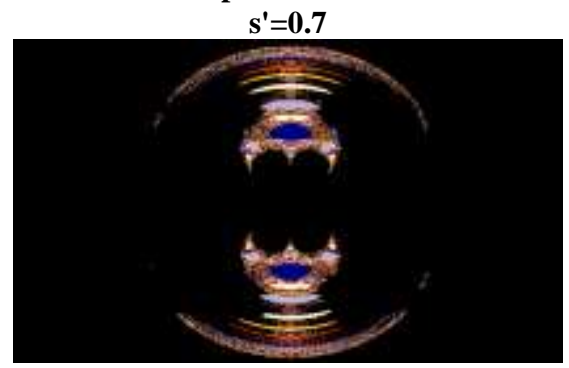

4.3 Relative Superior Mandelbar set for Bi-quadratic function:

Figure 1: Relative Superior Mandelbar set for $s=s^{\prime}=1$

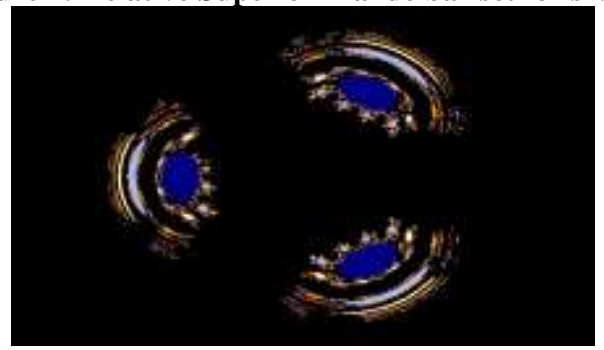

Figure 2: Relative Superior Mandelbar set for $s=0.4$

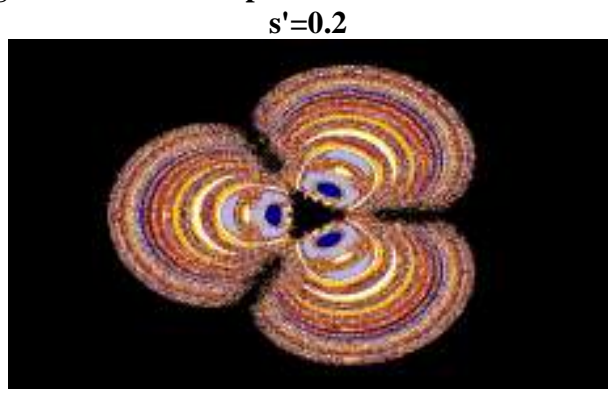

Figure 3: Relative Superior Mandelbar set for $\mathrm{s}=\mathbf{0 . 5}$, $\mathrm{s}^{\prime}=\mathbf{0 . 7}$ 


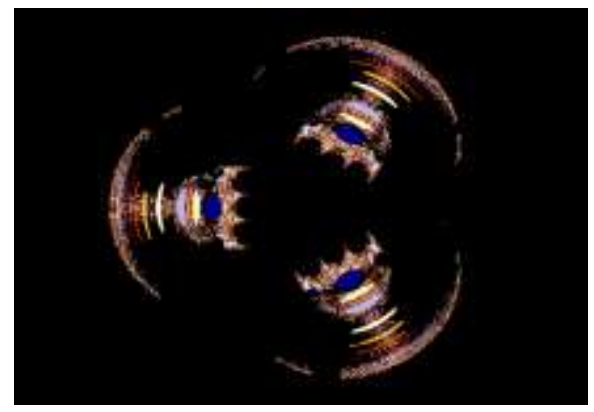

4.4. Generalization of Relative Superior Mandelbar sets: Figure 1: Relative Superior Mandelbar set for $s=0.5$, $\mathrm{s}^{\prime}=\mathbf{0 . 3}, \mathrm{n}=15$

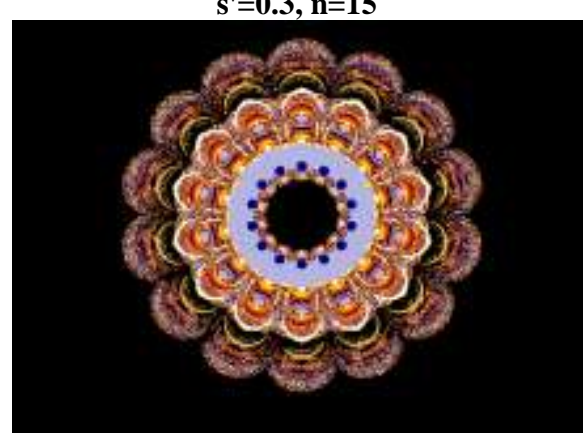

Figure 2: : Relative Superior Mandelbar set for $\mathrm{s}=\mathbf{0 . 5}$, $\mathrm{s}^{\prime}=0.2, \mathrm{n}=19$

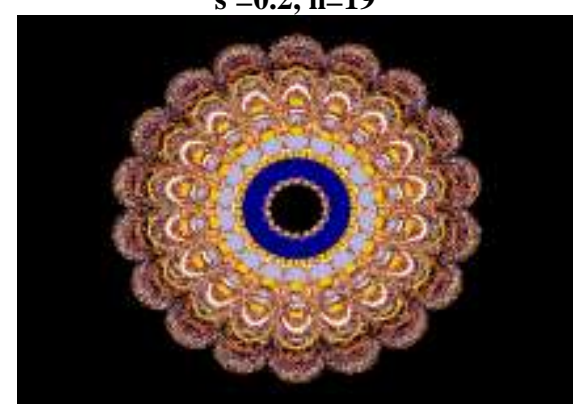

Figure 3: Relative Superior Multicorns for $\mathrm{s}=0.8$,

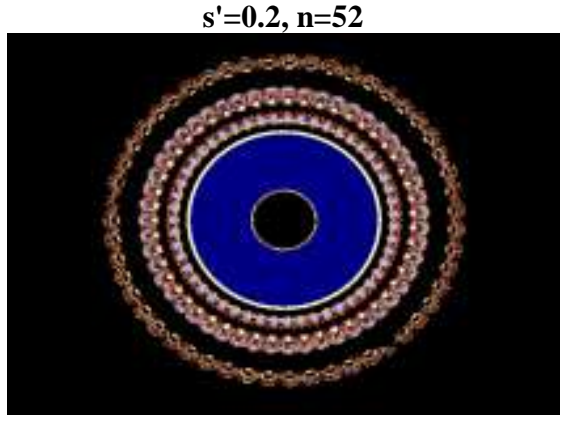

\section{GENERATION OF RELATIVE SUPERIOR JULIA SETS FOR MANDELBAR SETS}

We present here some filled Relative Superior Julia sets for quadratic, cubic and biquadratic function. 6.1 Relative Superior Julia sets for Quadratic:
Figure 1: Relative Superior Julia Set for $s=0.4, s^{\prime}=0.1$ $c=-0.04164390139+0.006005097 i$

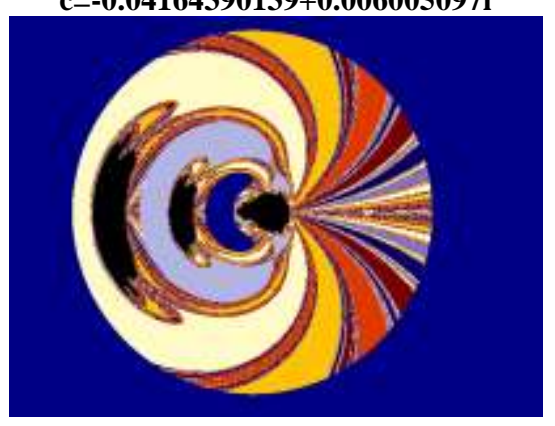

Figure 2: Relative Superior Julia Set for, $s=0.6, s^{\prime}=0.2$ $c=-0.08166620257-0.00739899807 i$

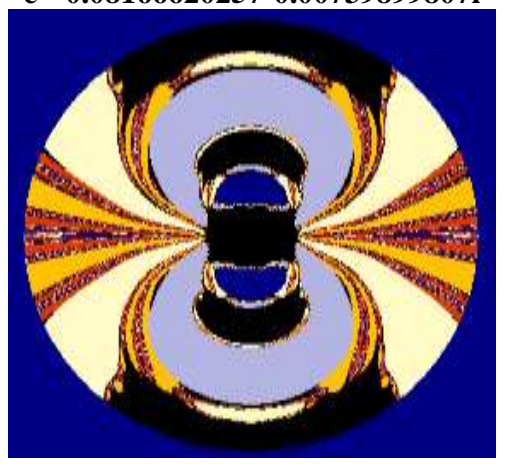

6.2 Relative Superior Julia sets for Cubic function:

Figure 1: Relative Superior Julia for $\mathrm{s}=0.4, \mathrm{~s}^{\prime}=0.2$ $c=-0.0189704705+0.02867852789 \mathrm{i}$

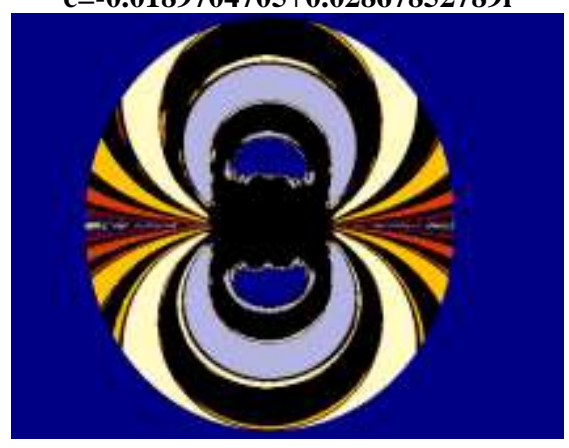

Figure 2: Relative Superior Julia Set for $s=0.5, s^{\prime}=0.7 c=-$ 0.003854849909-0.01666833389i

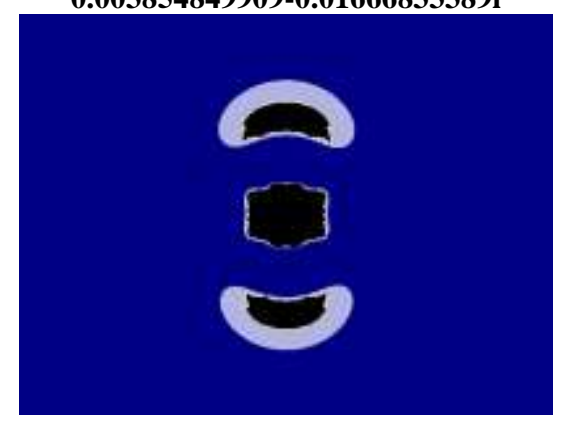


6.3 Relative Superior Julia sets for Bi-quadratic function:

Figure 1: Relative Superior Julia for $s=0.4, s^{\prime}=0.2$ $c=-0.03408609109+0.04379414848 i$

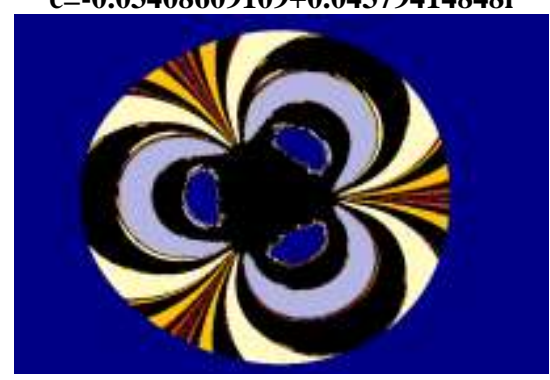

Figure 2: Relative Superior Julia for $s=0.5, s^{\prime}=0.7$ $c=-0.0189704705-0.001552713296 \mathrm{i}$

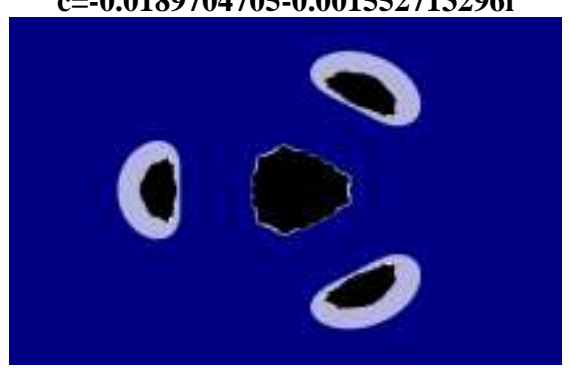

\section{CONCLUSION:}

In the dynamics of antipolynomial of complex polynomial $z^{\prime n}+c$, where $n \geq 2$, there exist many Mandelbar sets for a value of $n$ with respect to Relative Superior orbit. Further, for the odd values of $n$, all the Relative Superior Mandelbar sets are symmetrical objects, and for even values of $n$, all the Relative Superior Mandelbar sets are symmetrical about $\mathrm{x}$-axis. Besides this, our antifractals are different from the normal Tricorns and Multicorns as they have (n-1) wings.

\section{REFERENCES}

[1] B. Branner, The Mandelbrot Set, Proceedings of Symposia in Applied Mathematics39 (1989), 75-105. Published as Chaos and Fractals: The Mathematics Behind the Computer Graphics, ed. R. L. Devaney, L. Keen.

[2] P. Blanchard, Complex Analytic Dynamics on the Riemann Sphere, Bulletin of the American Mathematical Society 11, 1 (1984), 85-141.

[3] Y. S. Chauhan, R. Rana and A. Negi, New Tricorns and Multicorns of Ishikawa Iterates, In Press, Int. Journal of Computer Application (Oct. 2010 Edition).

[4] W. D. Crowe, R. Hasson, P. J. Rippon, and P. E. D. Strain-Clark, "On the structure of the Mandelbar set", Nonlinearity(2)(4)(1989), 541-553. MR1020441.

[5] S. Dhurandar, V. C. Bhavsar and U. G. Gujar, "Analysis of z-plane fractal images from $z \leftarrow z^{\alpha}+c$ for $\alpha<0$, Computers and Graphics 17, 1 (1993), 89-94.
[6] Robert L. Devaney, "A First Course in Chaotic Dynamical Systems: Theory and Experiment", Addison-Wesley, 1992. MR1202237.

[7] U. G. Gujar and V. C. Bhavsar, Fractals from $z \leftarrow z^{\alpha}+c$ in the Complex c-Plane, Computers and Graphics 15, 3 (1991), 441-449.

[8] U. G. Gujar, V. C. Bhavsar and N. Vangala, Fractals from $z \leftarrow z^{\alpha}+c$ in the Complex z-Plane, Computers and Graphics 16, 1 (1992), 45-49.

[9] E. F. Glynn, The Evolution of the Gingerbread Man, Computers and Graphics 15,4 (1991), 579-582.

[10] S. Ishikawa, "Fixed points by a new iteration method", Proc. Amer. Math. Soc.44 (1974), 147-150.

[11] Eike Lau and Dierk Schleicher, "Symmetries of fractals revisited.", Math. Intelligencer (18)(1)(1996), 45-51.

[12] B. B. Mandelbrot, The Fractal Geometry of Nature, W. H. Freeman, New York, 1983.

[13] J. Milnor, "Dynamics in one complex variable; Introductory lectures", Vieweg (1999).

[14] N. Shizuo and Dierk Schleicher, "Non-local connectivity of the tricorn and multicorns", Dynamical systems and chaos (1) (Hachioji, 1994), 200-203, World Sci. Publ., River Edge, NJ, 1995. MR1479931.

[15] N. Shizuo and Dierk Schleicher, "On multicorns and unicorns: I. Antiholomorphic dynamics. hyperbolic components and real cubic polynomials", Internat. J. Bifur. Chaos Appl. Sci. Engrg, (13)(10)(2003), 28252844.

[16] Ashish Negi, "Generation of Fractals and Applications", Thesis, Gurukul Kangri Vishwvidyalaya, (2005).

[17] H. Peitgen and P. H. Richter, The Beauty of Fractals, Springer-Verlag, Berlin,1986.

[18] H. Peitgen, Jurgens and Saupe, "Chaos and Fractals, Springer-Verlag”, NewYork, Inc., 1992.

[19] R. Rana, Y. S. Chauhan and A. Negi, Non Linear dynamics of Ishikawa Iteration, In Press, Int. Journal of Computer Application (Oct. 2010 Edition).

[20] K. W. Shirriff, “An investigation of fractals generated by $z \rightarrow z^{-n}+c$,, Computers and Graphics 13, 4 (1993), 603-607.

[21] R. Winters, "Bifurcations in families of Antiholomorphic and biquadratic maps", Thesis, Boston Univ. (1990). 